\title{
Inhibition of FHL1 inhibits cigarette smoke extract-induced proliferation in pulmonary arterial smooth muscle cells
}

\author{
YUPING LI ${ }^{1}$, GUIMEI PU ${ }^{2}$, CHENGSHUI CHEN ${ }^{1}$ and LI YANG $^{1}$ \\ ${ }^{1}$ Department of Respiratory Medicine, The First Affiliated Hospital of Wenzhou Medical University, \\ Wenzhou, Zhejiang 325000; ${ }^{2}$ Department of Respiratory Medicine, Shaoxing \\ People's Hospital, Shaoxing, Zhejiang 312000, P.R. China
}

Received July 26, 2014; Accepted April 10, 2015

DOI: $10.3892 / \mathrm{mmr} .2015 .3787$

\begin{abstract}
Cigarette smoke can induce pulmonary vascular remodeling, which involves pulmonary artery smooth muscle cell (PASMC) proliferation, resulting in pulmonary hypertension in chronic obstructive pulmonary disease. FHL1 is a member of the FHL subfamily, characterized by an $\mathrm{N}$-terminal half LIM domain, followed by four complete LIM domains, and has been suggested to be critical in cell proliferation. However, the effects of FHL1 on cigarette smoke-induced PASMC proliferation and the precise molecular mechanism remain to be elucidated. The present study demonstrated that the protein expression of FHL1 correlated with cigarette smoke extract (CSE)-induced PASMC proliferation. Knockdown of the expression of FHL1 using siRNA significantly suppressed cell proliferation and inhibited the cell cycle transition between the $G_{1}$ and $S$ phase by regulating the cyclin-dependent kinase pathway at the basal level and following CSE stimulation. By contrast, overexpressing FHL1 using an adenovirus increased cell proliferation and promoted the cell cycle transition between the $\mathrm{G}_{1}$ and $\mathrm{S}$ phase. Furthermore, CSE significantly increased the protein expression of FHL1, however, exerted no effect on the mRNA expression levels. This alteration was due to the prolonged FHL1 half-life, leading to the antagonizing of protein degradation. Collectively, these data suggested that FHL1 may be involved in excessive cell proliferation and may represent a potential therapeutic target for pulmonary hypertension.
\end{abstract}

\section{Introduction}

Pulmonary arterial hypertension (PAH) is a fatal and progressive disease, which frequently results in the elevation of pulmonary artery pressure, right ventricular failure and

Correspondence to: Miss. Li Yang, Department of Respiratory Medicine, The First Affiliated Hospital of Wenzhou Medical University, 2 Fuxue Lane, Wenzhou, Zhejiang 325000, P.R. China E-mail: yanglimedmail@163.com

Key words: pulmonary arterial hypertension, pulmonary artery smooth muscle cells, cell proliferation, cell cycle, FHL1 mortality (1-3). Vascular remodeling is the pathological hallmark of PAH, leading to narrowing and obstruction of small pulmonary arteries. The increased proliferation of pulmonary artery smooth muscle cells (PASMCs) is a pivotal contributor to vascular wall hypertrophy, vascular remodeling and the resulting forms of PAH $(4,5)$.

It is generally understood that smoking is a significant risk factor in the occurrence and development of chronic obstructive pulmonary disease (COPD) and pulmonary hypertension, by directly resulting in pulmonary vascular remodeling at the onset of the disease $(6,7)$. In addition, it has been reported that cigarette smoke may be involved in the mitogenic pathway of vascular smooth muscle cells (SMCs) in the bovine thoracic aorta, human greater saphenous vein, and aortic and iliac arteries (8-11). In addition, a previous study demonstrated that the expression levels of vasoactive mediators, including endothelin-1 and vascular endothelial growth factor, were increased in guinea pig lung vessels following chronic smoke exposure, and these mediators were reported to be closely associated with pulmonary vascular remodeling (12). However, the molecular mechanism underlying this process remains to be elucidated.

FHL1 is a $30 \mathrm{kDa}$ protein of the FHL subfamily, which is structurally characterized by an N-terminal half LIM domain, followed by four complete LIM domains (13). The LIM domain is a double-zinc finger protein-binding motif, a term used following earlier findings in the Lin11, Isl-1 and Mec-3 proteins (14). Previous studies have confirmed that FHL1 is highly expressed in skeletal muscle and in the heart $(13,15)$, and is suggested to contribute to sarcomere synthesis, assembly and biomechanical stress sensing $(16,17)$. Although considerably lower expression levels have been detected in several other tissue types, including colon, small intestine and prostate tissues (15), a previous study revealed that increased expression of FHL1 may be involved in the prognosis of Hirschsprung's disease (18). FHL1 deficiency was reported to significantly suppress proliferation, but exhibit no effect on the apoptosis of rat aortic SMCs (19). Additionally, Kwapiszewska et al demonstrated that knockdown of FHL1 markedly inhibited hypoxia-induced PASMC migration and proliferation (20). These results indicated that FHL1 is critical in the remodeling process during PAH. However, the effects of FHL1 on cigarette smoke-induced PASMC proliferation and its precise molecular mechanism remain to be elucidated. 
Accumulating evidence suggests that cell cycle progression is governed precisely at various biological checkpoints by cyclin proteins, cyclin-dependent kinases (CDK) and CDK inhibitors (CDKIs) (21). Among the cyclin families, cyclin D1 is a critical regulator of the progression of the cell cycle and has been demonstrated to be important in the proliferation of SMCs from vessels, airways and intestine (22-24). Additionally, the $\mathrm{G}_{1}$ to $\mathrm{S}$ phase transition checkpoint is regulated by CDK4 and CDK6, the activities of which are facilitated by cyclin D1, but are attenuated by p27 (25).

The present study used small interfering (si)RNA and adenovirus transfection methods to investigate the effects of FHL1 on CSE-induced PASMC proliferation and on the pathogenesis of PAH induced by cigarette smoke.

\section{Materials and methods}

Materials and reagents. Dulbecco's modified Eagle's medium (DMEM), fetal bovine serum (FBS), penicillin and streptomycin were purchased from Gibco Life Technologies (Carlsbad, CA, USA). All other reagents were purchased from Sigma-Aldrich (St. Louis, MO, USA), unless otherwise specified.

Cell isolation and culture. Primary rat PASMCs were isolated and cultured, as previously described (26). Briefly, 20 male Sprague-Dawley rats were obtained from the Animal Experiment Center of Wenzhou Medical University (Wenzhou, China) and were housed alone with a 12:12 h light/dark cycle with free access to water and food at room temperature. All animal experiments were approved by the Committee on the Ethics of Animal Experiments of Wenzhou Medical University and were performed in accordance with the Wenzhou Medical University Guidelines for the Ethical Care of Animals (WYDW2012-0032). At the age of 12 weeks, the rats were anesthetized with $100 \mathrm{mg} / \mathrm{kg}$ intraperitoneal ketamine and $5 \mathrm{mg} / \mathrm{kg}$ intraperitoneal xylazine. Subsequently, the distal pulmonary arteries were isolated and immersed immediately in Hanks' solution containing collagenase $(1.5 \mathrm{mg} / \mathrm{ml})$ for $20 \mathrm{~min}$. Following incubation at $37^{\circ} \mathrm{C}$, a thin layer of adventitia and endothelium were carefully stripped off. The PASMCs were then harvested by digesting the remaining smooth muscle with collagenase $(2.0 \mathrm{mg} / \mathrm{ml})$ and elastase $(0.5 \mathrm{mg} / \mathrm{ml})$ for $40 \mathrm{~min}$, and were cultured in DMEM, containing 10\% FBS, $100 \mathrm{U} / \mathrm{ml}$ penicillin and $100 \mathrm{U} / \mathrm{ml}$ streptomycin at $37^{\circ} \mathrm{C}$ in a $5 \% \mathrm{CO}_{2}$ atmosphere for 5 7 days. The cells were identified using immunochemistry and immunofluorescent staining the of $\alpha$-SM-actin antibody (AA132; 1:100; Beyotime Institiute of Biotechnology, Jiangsu, China). For all experiments, PASMCs between passages three and six were used, which were made quiescent by replacing the medium with FBS-free DMEM for $24 \mathrm{~h}$ prior to treatments.

Preparation of CSE solution. CSE was prepared freshly for each experiment, as described previously (27). Briefly, the smoke derived from one Double Happiness cigarette (Shanghai Tobacco Corporation, Shanghai, China) was drawn slowly into a $50 \mathrm{ml}$ syringe, passed through $30 \mathrm{ml}$ DMEM and was repeated for five draws of $50 \mathrm{ml}$ of the syringe. The resulting solution, which was expressed as '100\%' final concentration, was then adjusted to $\mathrm{pH} 7.4$ using concentrated $\mathrm{NaOH}$, filtered $(0.25 \mu \mathrm{m}$ size) for sterilization and diluted in DMEM to the required concentration $(1,2,5,10$ and $20 \%)$ for the experiment.

Cell proliferation and assessment of DNA synthesis. Cell proliferation was assessed using a Cell Counting kit-8 (CCK-8; Dojindo, Tokyo, Japan), according to the manufacturer's instructions. The PASMCs were plated into 96-well plates at a density of $1 \times 10^{4}$ cells $/ \mathrm{ml} /$ well and $10 \mu \mathrm{l}$ CCK- 8 reagent was added and incubated for $2 \mathrm{~h}$ at $37^{\circ} \mathrm{C}$. The absorbance was measured at $450 \mathrm{~nm}$ using a microplate reader (Multiskan Spectrum; Thermo Fisher Scientific, Pittsburgh, PA, USA).

The present study also examined the BrdU incorporation to measure DNA synthesis. The cells $\left(2 \times 10^{5}\right)$ were incubated with $50 \mathrm{mM} \mathrm{BrdU}$ for $4 \mathrm{~h}$ at $37^{\circ} \mathrm{C}$ and subsequently fixed with $4 \%$ paraformaldehyde in $0.01 \mathrm{M}$ cold phosphate buffer saline (PBS; pH 7.4). The cells were permeabilized with $2 \% \mathrm{HCI}$ containing $0.4 \%$ Triton X-100 for $15 \mathrm{~min}$. Following incubation with the monoclonal mouse anti-BrdU monoclonal antibody (1:50; ab12219; Abcam, Cambridge, MA, USA) at $4^{\circ} \mathrm{C}$ overnight, the samples were treated with biotinylated goat anti-mouse immunoglobulin G antibody (1:100; \#7056; Cell Signaling Technology, Inc., Danvers, MA, USA) for $60 \mathrm{~min}$ and subsequently stained with diaminobenzidene. PBS was used as a negative control by replacing the primary antibodies. The percentage of positively stained cells was determined by counting the numbers of stained cells and the total cells using a Nikon Eclipse E600FN microscope (Nikon, Tokyo, Japan).

Cell cycle analysis. The PASMCs were harvested by centrifugation at $200 \mathrm{x}$ g for $5 \mathrm{~min}$ at $4^{\circ} \mathrm{C}$. The pellets were washed with PBS and fixed in $70 \%$ ethanol overnight at $-20^{\circ} \mathrm{C}$. The samples were subsequently resuspended in PBS, containing propidium iodide $(50 \mu \mathrm{g} / \mathrm{ml})$, DNase-free RNase $(10 \mu \mathrm{g} 1 \mathrm{ml})$, $0.1 \%$ sodium citrate and $0.1 \%$ TritonX-100. The DNA content was analyzed using a Beckman EPICS XL flow cytometer (Beckman Coulter, Miami, FL, USA).

Terminal deoxynucleotidyl transferase dUTP nick end labeling (TUNEL). DNA fragmentation, a marker of apoptosis, was assessed using a TUNEL assay, as previously described (28). The cells $\left(2 \times 10^{5}\right)$ were fixed with $4 \%$ paraformaldehyde and permeabilized for $30 \mathrm{~min}$ using $70 \%$ ethanol on ice. Cell apoptosis was measured using an In situ Cell Death Detection kit $^{\circledR}$ (Roche, Basel, Switzerland), according to the manufacturer's instructions. The positive cells were visualized with the Nikon Eclipse E600FN microscope and the percentage of positive cells was determined by counting the numbers of TUNEL positive cells and the total cells.

Transfection of PASMCs with stealth siRNA. The sequence of the stealth siRNA duplex oligoribonucleotides against the rat FHL1 gene (GenBank accession no. NM_001033926.2) was 5'-UGCCAAGCAUUGCGUGAAA-3', and its corresponding complementary strand was 5'-CUAAGGAGGUGGACA UAA-3' (Santa Cruz Biotechnology, Inc., Dallas, TX, USA). The siRNA were transiently transfected using Lipofectamine RNAi max reagent (Applied Biosystems, Foster City, CA, USA), according to the manufacturer's instructions, and a negative stealth siRNA sequence was used as a control. Briefly, 
the siRNA and Lipofectamine RNAi max reagent were mixed and diluted in FBS-free DMEM. Following coincubation for $15 \mathrm{~min}$ at room temperature, the mixture was added to the PASMCs in a quiescent state and gently agitated to ensure uniform distribution. The transfection mixture was removed following incubation for $6 \mathrm{~h}$ at $37^{\circ} \mathrm{C}$ and complete medium was added for further incubation at $37^{\circ} \mathrm{C}$ for $48 \mathrm{~h}$.

Adenovirus expressing FHL1 infection. Full-length FHL1 cDNA was amplified and cloned into a pAdTrack-CMV plasmid (Invitrogen Life Technologies, Carlsbad, CA, USA), according to the manufacturer's instructions. The recombinant pAdTrack-CMV shuttle plasmids containing the FHL1 gene were linearized by $P a c I$ digestion and were transfected into 293A cells using Lipofectamine RNAi max reagent to produce a recombinant adenovirus. Viruses were packaged and amplified in 293A cells and purified using $\mathrm{CsCl}$ (Sigma-Aldrich) banding followed by dialysis against $10 \mathrm{mmol} / \mathrm{l}$ Tris-buffered saline with $10 \%$ glycerol. The titers of virus were assayed using a p24 ELISA kit (Cell Biolabs, San Diego, CA, USA). An adenovirus bearing LacZ was obtained from Clontech (Mountain View, CA, USA) and was used as the negative control. For overex-

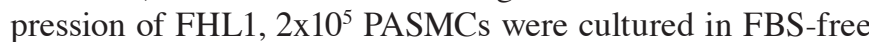
DMEM, containing the appropriate multiplicity of infection of adenovirus vectors for $6 \mathrm{~h}$ at $37^{\circ} \mathrm{C}$. The cells were then transferred into complete medium and cultured for $48 \mathrm{~h}$.

Western blot analysis. The total protein was harvested for western blot analysis, as described previously (29). Briefly, the cells were washed with cold PBS three times and subsequently lysed in radioimmunoprecipitation buffer (Beyotime Institute of Biotechnology), containing 1\% protease inhibitor cocktail (Merck, Darmstadt, Germany). Following determination of the protein content using a Bradford assay (Bio-Rad Laboratories, Inc., Hercules, USA), the proteins were resolved on $8-10 \%$ sodium dodecyl sulfate-polyacrylamide gels and transferred onto nitrocellulose membranes (Millipore, Billerica, MA, USA). The membranes were incubated with blocking buffer for $1 \mathrm{~h}$ and subsequently with the following primary antibodies at $4{ }^{\circ} \mathrm{C}$ overnight: Mouse-anti-FHL-1 monoclonal antibody (sc-374246), mouse-anti-PCNA monoclonal antibody (sc-25280) and mouse-anti- $\beta$-actin monoclonal antibody (sc-8432) (1:1,000; Santa Cruz Biotechnology, Inc.); rabbit-anti-cyclin D1 polyclonal antibody (\#2922), rabbit-anti-Ki67 monoclonal antibody (\#9129) and rabbit-anti-p27 monoclonal antibody (\#3686) (1:500; Cell Signaling Technology, Inc.). Following washing and incubation with horseradish peroxidase (HRP)-labeled goat anti-mouse IgG (A0216) or HRP-labeled goat anti-rabbit IgG (A0208) secondary antibodies (1:1,000; Beyotime Institute of Biotechnology) for $1 \mathrm{~h}$ at room temperature, the membranes were detected by a chemiluminescence system (Cell Signaling Technology, Inc.). Image quantification was performed using ImageJ software, version 1.37 (NIH, Bethesda, MD, USA).

Reverse transcription-quantitative polymerase chain reaction (RT-qPCR). The total RNA was isolated from the PASMCs using TRIzol reagent (Invitrogen Life Technologies), according to the manufacturer's instructions. A total of $1 \mu \mathrm{g}$ RNA was reverse transcribed using the SuperScript III First-Strand Synthesis system (Invitrogen Life Technologies).
A Fast SYBR ${ }^{\circledR}$ Green Master Mix kit (Applied Biosystems) was used for qPCR on a Fast RT-PCR system (ABI 7300; Applied Biosystems). A total of 40 cycles were performed as follows: $95^{\circ} \mathrm{C}$ for $15 \mathrm{sec}, 60^{\circ} \mathrm{C}$ for $1 \mathrm{~min}$ and $72^{\circ} \mathrm{C}$ for $30 \mathrm{sec}$. Relative expression was determined using GAPDH as an internal control and was reported using the $2^{-\Delta \Delta \mathrm{CT}}$ method. The specific primer sequences used for amplification were as follows: FHL1, forward 5'-GTGCCCTTGTACTCCACG TT-3' and reverse 5'-GTGTCCAAGGATGGCAAGAT-3' and GAPDH, forward 5'-ATGAGCCCCAGCCTTCTCCAT-3' and reverse 5'-GGTCGGAGTCAACGGATTTG-3'.

Statistical analysis. All data are expressed as the mean \pm standard error of mean. A one-way analysis of variance or an unpaired two-tailed Student t-test was used to analyze the differences between groups. $\mathrm{P}<0.05$ was considered to indicate a statistically significant difference. All statistical analyses were performed using SPSS16.0 software. (SPSS, Inc., Chicago, USA).

\section{Results}

Effects of CSE on cell proliferation and apoptosis. To investigate the effects of CSE on the proliferation of PASMCs, PASMCs were treated with $0,1,2,5,10$ or $20 \%$ CSE for $48 \mathrm{~h}$ and cell proliferation was determined using CCK-8 and BrdU incorporation assays. As shown in Fig. 1A and B, CSE at low concentrations of $1 \%$ significantly increased the number of cells by $19 \%$ and BrdU incorporation by $21 \%$, compared with the control $(0 \%)$. The peak increase in cell number $(69 \%)$ and BrdU incorporation (78\%) were observed at a concentration of 5\%. Notably, CSE at high concentrations (20\%) exhibited a significant inhibition on cell proliferation. Furthermore, no significant effect on cell apoptosis was observed at any of the CSE concentrations (Fig. 1C). In addition, the PASMCs were treated with 5\% CSE for different durations, and cell proliferation was examined. The results from the CCK- 8 and BrdU incorporation assays revealed that cell proliferation was triggered from $12 \mathrm{~h}$ and reached a peak at $48 \mathrm{~h}$ (Fig. 1D and E). Although incubation of CSE for $72 \mathrm{~h}$ marginally increased the percentage of apoptotic cells, no significant difference was observed compared with the control ( 0 h; Fig. $1 \mathrm{~F})$, indicating that CSE has no toxic effect on PASMCs. These data suggested that CSE induced the PASMC proliferation.

Protein expression of FHL1 parallels with the CSE-induced proliferation of PASMCs. To investigate whether the expression of FHL1 correlated with the rate of cell proliferation, the effect of CSE on the expression of FHL1 was determined. As shown in Fig. 2A, 5\% CSE induced the protein expression of FHL1 in a time-dependent manner. Compared with the control $(0 \mathrm{~h})$, the protein expression of FHL1 at 12, 24, $4872 \mathrm{~h}$ was increased $1.24 \pm 0.13,1.57 \pm 0.21,2.45 \pm 0.34$ and $2.32 \pm 0.32$-fold, respectively. The protein expression of FHL1 reached the maximal expression level at $48 \mathrm{~h}$, which paralleled with CSE-induced cell proliferation. To further confirm the effect of CSE on cell proliferation, the expression levels of two proliferation markers, PCNA and Ki67, were assessed. As expected, the expression levels of PCNA and Ki67 were increased following treatment with CSE in a time-dependent manner. Notably, the 


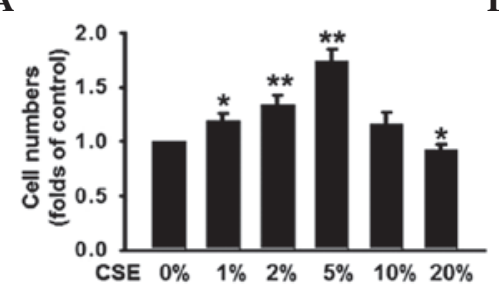

D

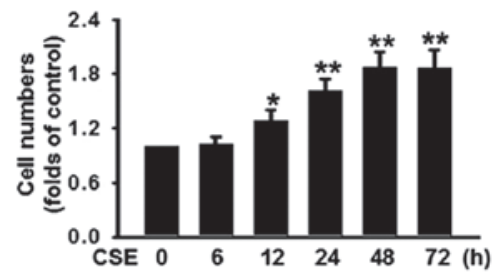

B

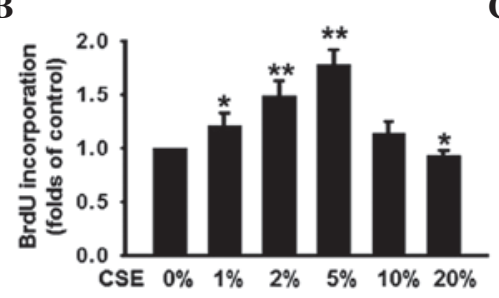

C

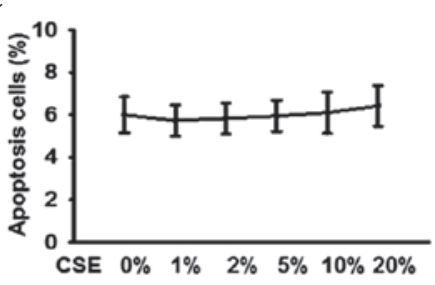

$\mathbf{F}$
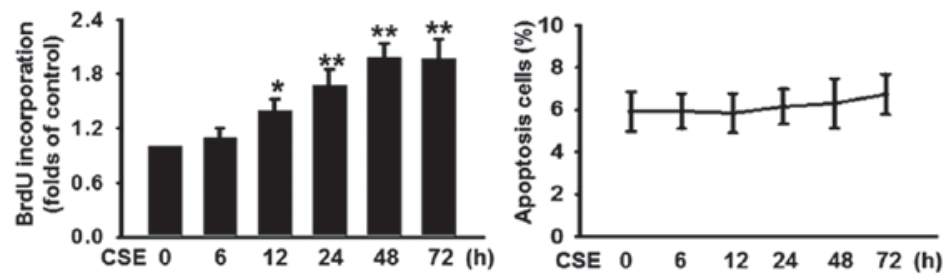

Figure 1. Effects of CSE on the proliferation and apoptosis of PASMCs. (A-C) PASMCs were incubated with CSE at different concentrations (0-20\%) for $48 \mathrm{~h}$. (B) Cell proliferation was determined using a (A) CCK-8 kit and (B) BrdU incorporation assay. (C) Cell apoptosis was detected using a TUNEL assay. (D-F) PASMCs were incubated with 5\% CSE for different durations as indicated. The proliferation of PASMCs was evaluated using a (D) CCK-8 kit and (E) BrdU incorporation assay. (F) Cell apoptosis was detected using a TUNEL assay. The $0 \%$ or $0 \mathrm{~h}$ groups were used as control groups. The data are expressed as the mean \pm standard error of the mean of six independent experiments ( $\mathrm{P}<0.05$ and ${ }^{* *} \mathrm{P}<0.01$, vs. control). CSE, cigarette smoke extract; PASMCs, pulmonary artery smooth muscle cells; CCK, cell counting kit; TUNEL, terminal deoxynucleotidyl transferase dUTP nick end labeling; BrdU, bromodeoxyuridine.

A
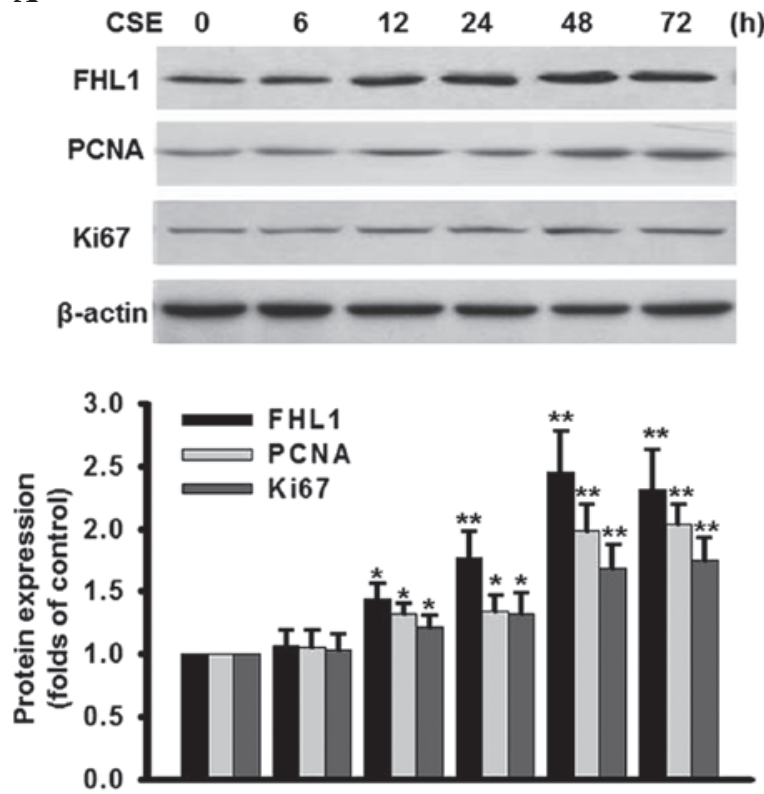

B

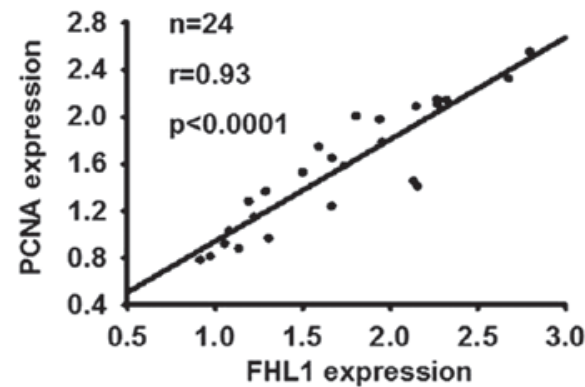

C

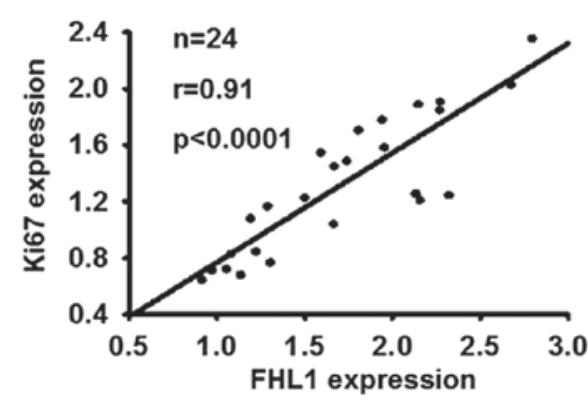

Figure 2. Protein expression of FHL1 is correlated with CSE-induced proliferation of PASMCs. (A) PASMCs were incubated with 5\% CSE for different durations, as indicated. The protein expression levels of FHL1, PCNA and Ki67 were detected usig western blot analysis, with $\beta$-actin as an internal control. The $0 \mathrm{~h}$ group was considered the control group All data are expressed as the mean \pm standard error of the mean ( $\mathrm{P}<0.05$ and ${ }^{* *} \mathrm{P}<0.01$, vs. control). The correlation between the expression levels of (B) FHL1 and PCNA or (C) FHL1 and Ki67 were analyzed. CSE, cigarette smoke extract; PASMCs, pulmonary artery smooth muscle cells.

protein expression of FHL1 was positively correlated with the protein expression levels of PCNA and Ki67 (Fig. 2B and C). These data suggested that increased expression of FHL1 may be involved in the CSE-induced proliferation of PASMCs.

FHL1 accelerates the proliferation of PASMCs. To determine whether FHL1 is involved in the CSE-induced proliferation of PASMCs, the effect of FHL1 knockdown on PASMC proliferation was determined. The silencing efficiency of the siRNA was detected using western blot and RT-qPCR analyses. Compared with the control, $20 \mathrm{nM}$ FHL1 siRNA significantly decreased the protein expression of FHL1 by $81 \%$ and its mRNA expression by $75 \%$, while the negative siRNA (Neg) caused no change in the mRNA or protein expression levels of FHL1 (Fig. 3A and B). FHL1 deficiency significantly decreased the cell number at the basal level and inhibited the increase of cell number induced by CSE (Fig. 3C). The result of BrdU incorporation revealed a similar tendency (Fig. 3D). The effect of FHL1 overexpression 
A

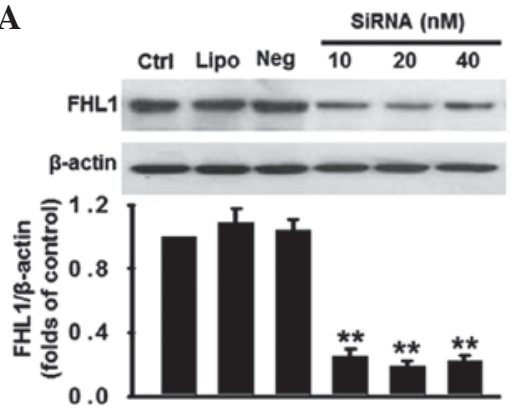

B

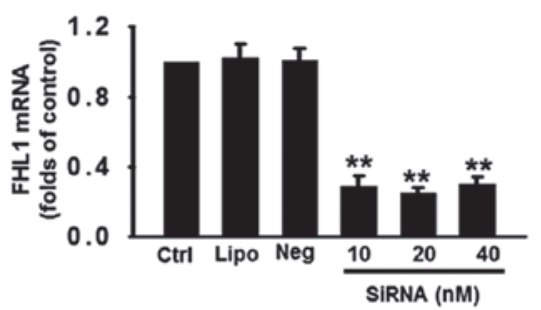

C

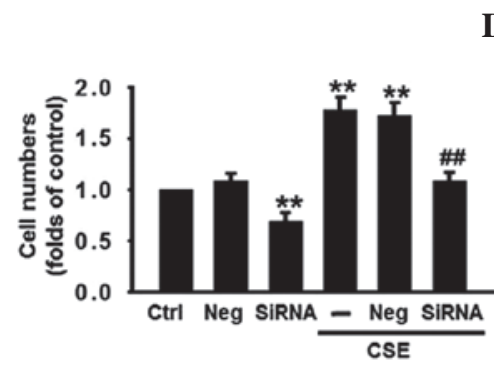

F

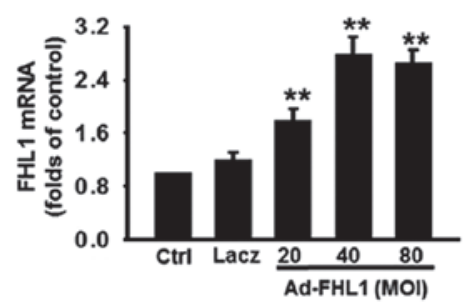

D

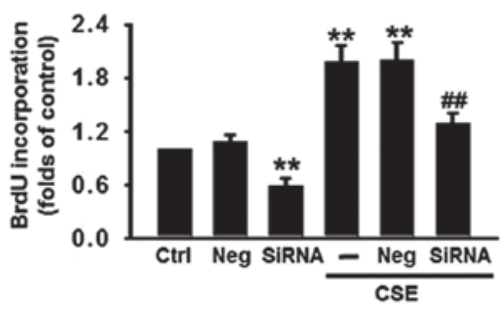

G

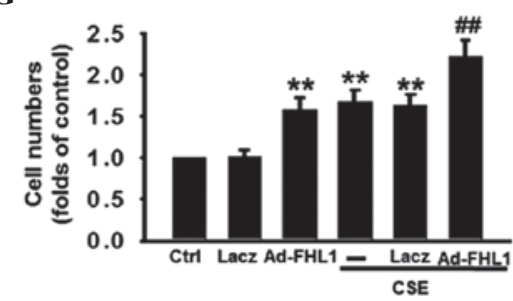

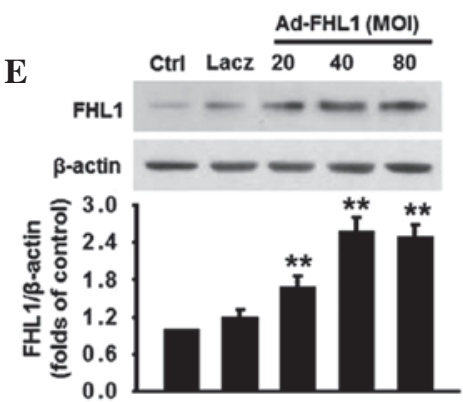

H

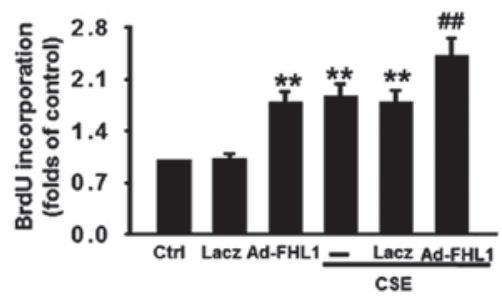

Figure 3. Effects of FHL1 on CSE-induced proliferation of PASMCs. (A and B) Silencing efficiency of siRNA was examined. The cells were transfected with different concentrations of FHL1-targeting siRNA (10, 20 or $40 \mathrm{nM}$ ) for $48 \mathrm{~h}$. The expression of FHL1 was determined using (A) western blot and (B) RT-qPCR analyses. Negative siRNA was used as a negative control. (C and D) FHL1 was knocked down using siRNA, as described for A and B, and the cell proliferation was assessed using (C) CCK-8 and (D) BrdU incorporation assays. (E and F) PASMCs were infected with adenovirus packaging an expression vector of FHL1 (Ad-FHL1; MOI, 20, 40 and 80) for $48 \mathrm{~h}$. The expression of FHL1 was detected using (E) western blot and (F) RT-qPCR analyses. Lacz was used as a negative control. (G and H) FHL1 was overexpressed, as described fot E and F, and the cell proliferation was assessed using (G) CCK-8 and (H) BrdU incorporation assays. All data are expressed as the mean \pm standard error of the mean $\left({ }^{*} \mathrm{P}<0.05\right.$ and ${ }^{* *} \mathrm{P}<0.01$, vs. Ctrl; ${ }^{\#} \mathrm{P}<0.05$ and ${ }^{\# \#} \mathrm{P}<0.01$, vs. CSE alone; $\mathrm{n}=6$ ). siRNA, small interfering RNA; RT-qPCR, reverse transcription-quantitative polymerase chain reaction; BrdU, bromodeoxyuridine; CCK-8, cell counting kit-8; MOI, multiplicity of infection; CSE, cigarette smoke extract; PASMCs, pulmonary artery smooth muscle cells; Ctrl, control; Neg, negative; Lipo, lipofectamine RNAi max reagent.

on cell proliferation was assessed to confirm the role of FHL1 in proliferation. Following the successful overexpression of FHL1, confirmed using western blotand RT-qPCR analyses (Fig. 3E and $F$ ), the proliferation of the PASMCs was markedly increased at the basal level and following CSE stimulation (Fig. 3G and $H)$. Negative siRNA and Lacz transfection caused no significant alteration to the rate of PASMCs proliferation at the basal level or following treatment with CSE.

Inhibition of FHLI inhibits the $G_{I} / S$ cell cycle transition. The effect of FHL1 on cell cycle status was also investigated in the present study. According to flow cytometric analysis, 5\% CSE reduced the proportion of cells in the $G_{0} / G_{1}$ phase between 69.3 and $48.9 \%$, and simultaneously increased the proportion of cells in the S phase between 21.3 and $38.7 \%$, compared with the control (Fig. 4A), which suggested that CSE promoted cell cycle progression and an increase in cells entry into the $\mathrm{S}$ phase. However, inhibition of FHL1 significantly decreased the percentage of cells in $S$ phase and resulted in $G_{0} / G_{1}$ cell cycle arrest at the basal level and following CSE stimulation, suggesting that the deficiency of FHL1 arrested the cell cycle in $G_{0} / G_{1}$ phase by preventing entrance into the $S$ phase in the PASMCs. By contrast, FHL1 overexpression decreased the percentage of cells in the $G_{1}$ phase and increased the percentage in the $\mathrm{S}$ phase, compared with the corresponding control (Fig. 4B). To investigate the molecular mechanisms by which FHL1 knockdown arrests cells at the $\mathrm{G}_{1} / \mathrm{S}$ transition, the expression levels of cyclin D1 and p27, which are involved in the regulation of the $G_{1}$ to $S$ phase transition checkpoint were investigated. The results demonstrated that silencing of FHL1 markedly decreased the expression of cyclin D1 at the basal level and inhibited the CSE-induced increase of the expression of cyclin D1. By contrast, the expression of p27 was increased at the basal level and restored following CSE stimulation (Fig. 4C). The inverse results were obtained in the group overexpressing FHL1 (Fig. 4D).

CSE induces the expression of FHL1 by increasing protein stability. To further investigate the mechanism by which CSE induced the expression of FHL1, the mRNA expression level 

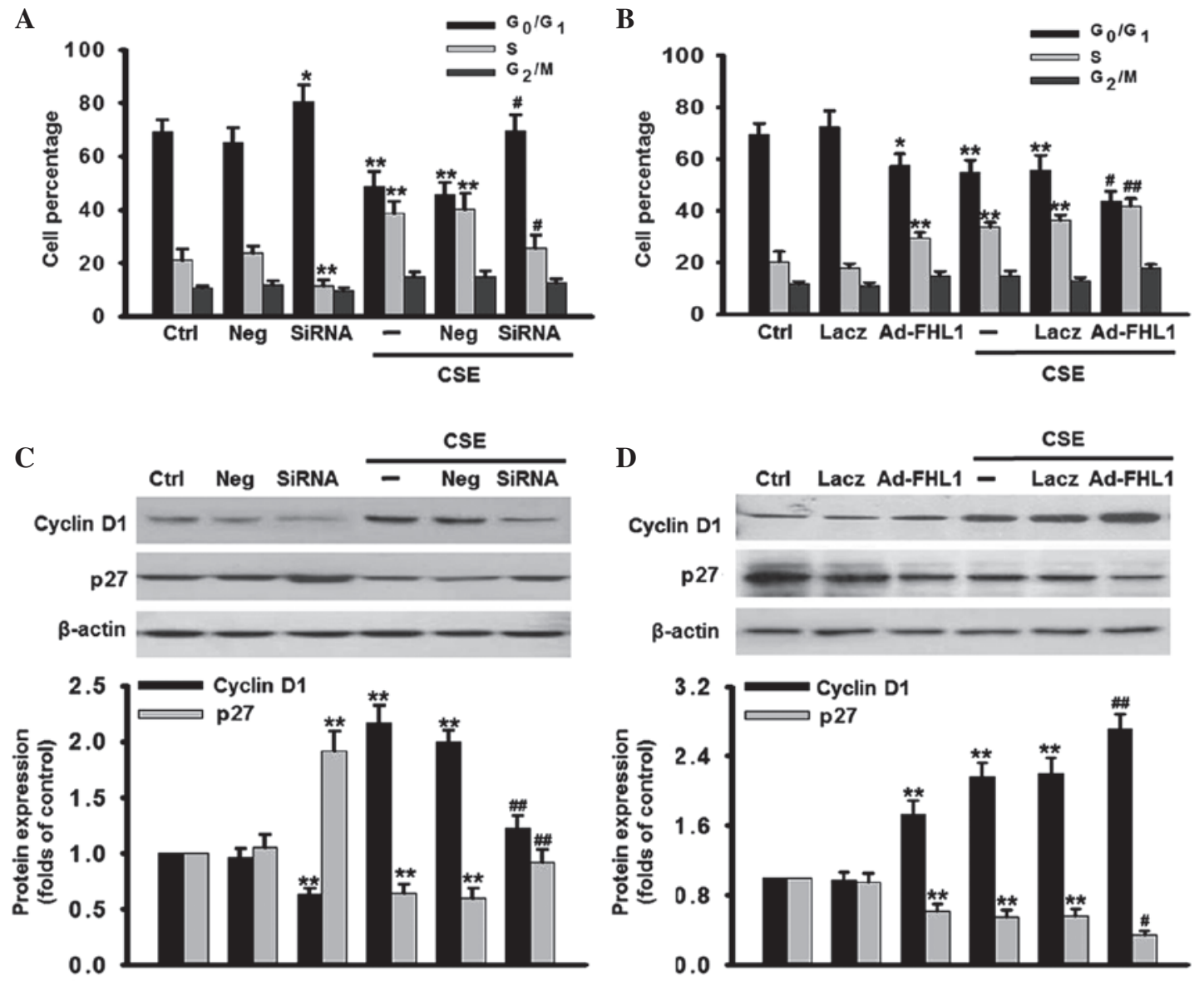

Figure 4. Effects of FHL1 on the cell cycle phases. FHL1 was (A) knocked down using siRNA or (B) overexpressed by adenovirus in the presence or absence of CSE for $48 \mathrm{~h}$. The cell cycle phases were determined by flow cytometry. The percentage of cells in $\mathrm{G}_{0} / \mathrm{G}_{1}, \mathrm{~S}, \mathrm{G}_{2} / \mathrm{M}$ phases were statistically analyzed (C and D) Following treatment, the expression levels of cyclin D1 and p27 were detected by western blotting, using $\beta$-actin as an internal control. The data are expressed as the mean \pm standard error of the mean $\left({ }^{*} \mathrm{P}<0.05,{ }^{* *} \mathrm{P}<0.01\right.$, vs. control; ${ }^{*} \mathrm{P}<0.05,{ }^{\# \#} \mathrm{P}<0.01$, vs. CSE alone; $\left.\mathrm{n}=6\right)$. siRNA, small interfering RNA; CSE, cigarette smoke extract; PASMCs, pulmonary artery smooth muscle cells.

A

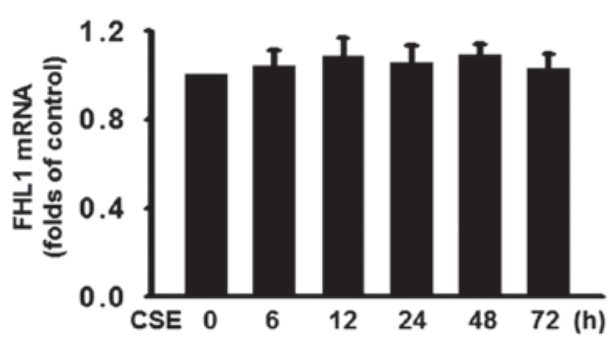

B

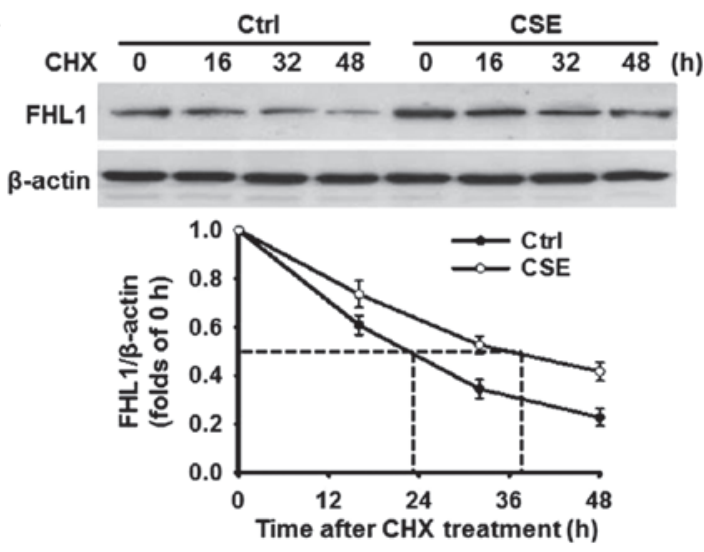

Figure 5. CSE prolongs half-life of the FHL1 protein. (A) The PASMCs were incubated with 5\% CSE for different durations, as indicated. The mRNA expression of FHL1 was detected by reverse transcription quantitative polymerase chain reaction. (B) The PASMCs were pre-treated with $5 \%$ CSE for $48 \mathrm{~h}$ and subsequently incubated with $10 \mu \mathrm{g} / \mathrm{ml} \mathrm{CHX}$ for different durations, as indicated. The protein expression of FHL1 was analyzed by western blotting, using $\beta$-actin as an internal control. All data are expressed as the mean \pm standard error of the mean. CSE, cigarette smoke extract; PASMCs, pulmonary artery smooth muscle cells; CHX, cycloheximide.

of FHL1 was determined. RT-qPCR analysis revealed that the mRNA expression of FHL1 remained unchanged following treatment with CSE (Fig. 5A), indicating that a post-transcriptional mechanism may be involved. Since the predominant mechanism involved in the modulation of protein expression is degradation, the present study determined whether CSE altered the protein stability of FHL1. The PASMCs were treated with or without 5\% CSE for $48 \mathrm{~h}$ and cycloheximide (CHX; $10 \mu \mathrm{g} / \mathrm{ml}$ ), a protein synthesis inhibitor, was added at various time points $(0,16,32$ and $48 \mathrm{~h})$. The results revealed that treatment of the 
PASMCs with CHX led to a time-dependent decrease in the protein expression of FHL1 in the two groups. Notably, the combination of CHX and CSE significantly changed the rate of FHL1 degradation, increasing the FHL1 half-life by $>12 \mathrm{~h}$ compared with the control (Fig. 5B). These results suggested that CSE upregulates FHL1, at least in part, at the post-translational level, rather than the transcriptional level.

\section{Discussion}

The results of the present study provided compelling evidence that the expression of FHL1 is associated with CSE-induced proliferation of PASMCs. The present study demonstrated that CSE-induced cell proliferation was accompanied by an increase in the protein expression of FHL1 in a time-dependent manner, determined using western blot analysis and a proliferation assay. In addition, it was revealed that FHL1 accelerated cell proliferation by promoting cell cycle transition between the $\mathrm{G} 1$ and $\mathrm{S}$ phase. Finally, CSE was found to be involved in maintaining the stability of the FHL1 protein. These data are the first, to the best of our knowledge, to confirm the key role of FHL1 in cell proliferation induced by cigarette smoke.

Cigarette smoke is a major risk factor in various types of disease, including PAH. As the predominant cause of hypertrophy and vascular remodeling, the increase of PASMC proliferation contributes to PAH $(5,30)$. Substantial evidence from animals and humans has suggested that smoking induces pulmonary vascular remodeling in patients with mild-to-moderate COPD in smokers with normal lung function (31-33). The present study demonstrated a biphasic nature of the effect of CSE on the proliferation of PASMCs. Low concentrations of CSE (1, 2 and $5 \%$ ) increased cell proliferation, while high concentrations exhibited a significant inhibition on cell proliferation. These results were in accordance with previous studies (34-36).

FHL1 is the most widely expressed member of the FHL subfamily, containing four complete and one half, highly conserved, LIM domains (37). LIM domains function as important mediators of protein-protein interactions in the cytoplasm and nucleus, and their functions are largely dependent upon their associated binding partners $(14,38,39)$, including $\alpha 5 \beta 1$ and $\alpha 7 \beta 1$ integrins $(40,41)$, muscle-specific RING finger proteins MuRF1 and MuRF2 (42), and other protein kinases, including ERK2 (17,43). Additionally, LIM domain proteins have been suggested to be involved in biomechanical stress responses, as structural adapters and as subcellular localizers $(16,44,45)$. A previous study demonstrated that silencing of FHL1 significantly decreased the migration and proliferation of PASMCs in a hypoxia-induced rat hypertension model, and defined a novel interaction between FHL1 and Talin1, which may be significant in the proliferation and migration of PASMCs (20). However, the potential effects of FHL1 on the CSE-induced proliferation of PASMCs remains to be elucidated. In the present study, CCK-8 and BrdU incorporation assays demonstrated that knockdown of FHL1 significantly decreased the proliferation of PASMCs, whereas overexpression of FHL1 induced the opposite effect. These findings are consistent with data from a previous study (20), but are novel, to the best of our knowledge, for CSE-induced cell proliferation. To further confirm the role of FHL1 in cell proliferation, the effects of FHL1 on cell-cycle distribution were assessed. Flow cytometry demonstrated that the upregulation of FHL1 promoted cell cycle progression between the $G_{1}$ and $S$ phase. Conversely, deficiency of FHL1 caused cell cycle arrest at the $\mathrm{G}_{1}$ phase. Cell cycle progression is a tightly controlled event, which is positively regulated by cyclins and CDKs, and negatively regulated by CDKIs (46). The present study demonstrated that loss of FHL1 almost eliminated CSE-induced expression of cyclin D1, which promotes transition between the $G_{1}$ and $S$ phase (21). In addition, FHL1 knockdown also reversed the inhibitory effect of CSE on the expression of p27, which is widely reported to restrict the $G_{1} / S$ transition in the cell cycle by suppressing several cyclin-CDK complexes (47). The inverse results were observed in FHL1 overexpressing cells. Together, these results demonstrated that FHL1 accelerated CSE-induced cell proliferation by regulating the expression levels of cyclin D1 and p27, which facilitated the cell cycle transition between the $\mathrm{G}_{1}$ and $\mathrm{S}$ phase.

As CSE induced the proliferation of PASMCs and the expression of FHL1, the present study investigated the correlation between the expression of FHL1 and cell proliferation. Western blot analysis and a proliferation assay revealed that the induction of cell proliferation by CSE was accompanied by an increase in the protein expression of FHL1 in the same time-dependent manner. Detection of the expression levels of Ki67 and PCNA, which are essential for DNA replication (48), further confirmed that the expression of FHL1 correlated with the rate of PASMC proliferation. Notably, CSE exerted no effect on the mRNA expression of FHL1, indicating that transcriptional regulation was not involved. A previous study demonstrated that hypoxia reduced the protein expression levels of FHLl in the lung, pulmonary artery and alveolar septae, but exhibited different effects on the mRNA expression in these tissues (20). Therefore, awareness of tissue- and stimulation-specific responses is required. It is well known that the predominant mechanism involved in the regulation of protein levels is degradation. The present study demonstrated that CSE significantly decreased the rate of FHL1 degradation, suggesting that protein stabilization at translational levels was involved, at least partially, in the CSE-induced increase in the expression of FHL1.

In conclusion, the results of the present study suggested that FHL1 is an important regulator in PASMC proliferation induced by cigarette smoke. Therefore, inhibition of FHL1 may offer a potential therapeutic strategy for the treatment of smokers with PAH.

\section{Acknowledgements}

This study was supported by the Zhejiang Natural Science Foundation (no.LQ13H010002) and the Science and Technology Planning Project of Wenzhou, China (no. Y20100292).

\section{References}

1. Marc Humbert, Olivier Sitbon and Gérald Simonneau: Treatment of Pulmonary Arterial Hypertension. N Engl J Med 351: 1425-1436, 2004.

2. Pidgeon GP, Tamosiuniene R, Chen G, Leonard I, Belton O, Bradford A and Fitzgerald DJ: Intravascular thrombosis after hypoxia-induced pulmonary hypertension: regulation by cyclooxygenase-2. Circulation 110: 2701-2707, 2004.

3. Mandegar M, Fung YC, Huang W, Remillard CV, Rubin LJ and Yuan JX: Cellular and molecular mechanisms of pulmonary vascular remodeling: role in the development of pulmonary hypertension. Microvasc Res 68: 75-103, 2004. 
4. Barberà JA, Peinado VI and Santos S: Pulmonary hypertension in chronic obstructive pulmonary disease. Eur Respir J 21: 892-905, 2003

5. Pietra GG, Capron F, Stewart S, et al: Pathologic assessment of vasculopathies in pulmonary hypertension. J Am Coll Cardiol 43 (Suppl 12): 25-32, 2004.

6. Wright JL, Cosio M and Churg A: Animal models of chronic obstructive pulmonary disease. Am J Physiol Lung Cell Mol Physiol 295: L1-L15, 2008.

7. Mandegar M, Fung YC, Huang W, Remillard CV, Rubin LJ and Yuan JX: Cellular and molecular mechanisms of pulmonary vascular remodeling: role in the development of pulmonary hypertension. Microvasc Res 68: 75-103, 2004.

8. Carty CS, Huribal M, Marsan BU, Ricotta JJ and Dryjski M: Nicotine and its metabolite cotinine are mitogenic for human vascular smooth muscle cells. J Vasc Surg 25: 682-628, 1997.

9. Nishio E and Watanabe Y: Cigarette smoke extract is a modulator of mitogenic action in vascular smooth muscle cells. Life Sci 62: 1339-1347, 1998.

10. Li JM, Cui TX, Shiuchi T, Liu HW, Min LJ, Okumura M, Jinno T, Wu L, Iwai M and Horiuchi M: Nicotine enhances angiotensin II-induced mitogenic response in vascular smooth muscle cells and fibroblasts. Arterioscler Thromb Vasc Biol 24: 80-84, 2004.

11. Jacob T, Clouden N, Hingorani A and Ascher E: The effect of cotinine on telomerase activity in human vascular smooth muscle cells. J Cardiovasc Surg (Torino) 50: 345-349, 2009.

12. Wright JL, Tai $\mathrm{H}$ and Churg A: Vasoactive mediators and pulmonary hypertension after cigarette smoke exposure in the guinea pig. J Appl Physiol (1985) 100: 672-678, 2006.

13. Lee SM, Tsui SK, Chan KK, Garcia-Barcelo M, Waye MM, Fung KP, Liew CC and Lee CY: Chromosomal mapping, tissue distribution and cDNA sequence of four-and-a-half LIM domain protein 1 (FHL1). Gene 216: 163-170, 1998

14. Bach I: The LIM domain: regulation by association. Mech Dev 91: 5-17, 2000.

15. Greene WK, Baker E, Rabbitts TH and Kees UR: Genomic structure, tissue expression and chromosomal location of the LIM-only gene, SLIM1. Gene 232: 203-207, 1999.

16. Chu PH, Ruiz-Lozano P, Zhou Q, Cai C and Chen J: Expression patterns of FHL/SLIM family members suggest important functional roles in skeletal muscle and cardiovascular system. Mech Dev 95: 259-265, 2000.

17. Sheikh F, Raskin A, Chu PH, Lange S, Domenighetti AA, Zheng M, Liang X, Zhang T, Yajima T, Gu Y, Dalton ND, et al: An FHL1-containing complex within the cardiomyocyte sarcomere mediates hypertrophic biomechanical stress responses in mice. J Clin Invest 118: 3870-3880, 2008.

18. Wang LL, Gu H, Fan Y, Zhang Y, Wu D, Miao JN, Huang TC, $\mathrm{Li} \mathrm{H}$ and Yuan ZW: Up-regulated FHL1 expression maybe involved in the prognosis of Hirschsprung's disease. Int J Med Sci 11: 262-267, 2014.

19. Weng J,Liao M,Zou S, Bao J,Zhou J, Qu L, Feng R, Feng X, Zhao Z and Jing Z: Downregulation of FHL1 expression in thoracic aortic dissection: implications in aortic wall remodeling and pathogenesis of thoracic aortic dissection. Ann Vasc Surg 25: 240-247, 2011.

20. Kwapiszewska G, Wygrecka M, Marsh LM, Schmitt S, Trösser R, Wilhelm J, Helmus K, Eul B, Zakrzewicz A, Ghofrani HA, Schermuly RT, et al: Fhl-1, a new key protein in pulmonary hypertension. Circulation 118: 1183-1194, 2008.

21. Morgan DO: Principles of CDK regulation. Nature 374: 131-134, 1995.

22. Zeng DX, Liu XS, Xu YJ, Wang R, Xiang M, Xiong WN, Ni W and Chen SX: Plasmid-based short hairpin RNA against cyclin D1 attenuated pulmonary vascular remodeling in smoking rats Microvasc Res 80: 116-122, 2010.

23. Pera T, Gosens R, Lesterhuis AH, Sami R, van der Toorn M, Zaagsma J and Meurs H: Cigarette smoke and lipopolysaccharide induce a proliferative airway smooth muscle phenotype. Respir Res 11: 48, 2010.

24. Kuemmerle JF, Zhou H and Bowers JG: IGF-I stimulates human intestinal smooth muscle cell growth by regulation of G1 phase cell cycle proteins. Am J Physiol Gastrointest Liver Physiol 286: G412-G419, 2004.

25. Nakayama K, Ishida N, Shirane M, Inomata A, Inoue T, Shishido N, Horii I, Loh DY and Nakayama K: Mice lacking p27(Kip1) display increased body size, multiple organ hyperplasia, retinal dysplasia and pituitary tumors. Cell 85: 707-720, 1996.

26. Golovina VA and Blaustein MP: Preparation of primary cultured mesenteric artery smooth muscle cells for fluorescent imaging and physiological studies. Nat Protoc 1: 2681-2687, 2006.
27. Oltmanns U, Chung KF, Walters M, John M and Mitchell JA: Cigarette smoke induces IL-8, but inhibits eotaxin and RANTES release from airway smooth muscle. Respir Res 6: 74, 2005.

28. Wang Q, Li X, Chen Y, Wang F, Yang Q, Chen S, Min Y, Li X and Xiong L: Activation of epsilon protein kinase C-mediated anti-apoptosis is involved in rapid tolerance induced by electroacupuncture pretreatment through cannabinoid receptor type 1. Stroke 42: 389-396, 2011.

29. Leopold JA, Dam A, Maron BA, Scribner AW, Liao R, Handy DE, Stanton RC, Pitt B and Loscalzo J: Aldosterone impairs vascular reactivity by decreasing glucose-6-phosphate dehydrogenase activity. Nat Med 13: 189-197, 2007.

30. Rabinovitch M: The mouse through the looking glass: a new door into the pathophysiology of pulmonary hypertension. Circ Res 94: 1001-1004, 2004.

31. Liu SQ and Fung YC: Changes in the structure and mechanical properties of pulmonary arteries of rats exposed to cigarette smoke. Am Rev Respir Dis 148: 768-777, 1993.

32. Peinado VI, Barbera JA, Ramirez J, Gomez FP, Roca J, Jover L, Gimferrer JM and Rodriguez-Roisin R: Endothelial dysfunction in pulmonary arteries of patients with mild COPD. Am J Physiol 274: L908-L913, 1998.

33. Washko GR: Diagnostic imaging in COPD. Semin Respir Crit Care Med 31: 276-285, 2010.

34. Luppi F, Aarbiou J, van Wetering S, Rahman I, de Boer WI, Rabe KF and Hiemstra PS: Effects of cigarette smoke condensate on proliferation and wound closure of bronchial epithelial cells in vitro: role of glutathione. Respir Res 6: 140, 2005.

35. Liu K, Liu XS, Yu MQ and Xu YJ: Change of extracellular signal-regulated kinase expression in pulmonary arteries from smokers with and without chronic obstructive pulmonary disease. Exp Lung Res 39: 162-172, 2013.

36. Zeng DX, Xu YJ, Liu XS, Wang R and Xiang M: Cigarette smoke extract induced rat pulmonary artery smooth muscle cells proliferation via PKC $\alpha$-mediated cyclin D1 expression. J Cell Biochem 112: 2082-2088, 2011.

37. Shathasivam T, Kislinger T and Gramolini AO: Genes, proteins and complexes: the multifaceted nature of FHL family proteins in diverse tissues. J Cell Mol Med 14: 2702-2720, 2010.

38. Kadrmas JL and Beckerle MC: The LIM domain: from the cytoskeleton to the nucleus. Nat Rev Mol Cell Biol 5: 920-931, 2004.

39. Schmeichel KL and Beckerle MC: The LIM domain is a modular protein-binding interface. Cell 79: 211-219, 1994.

40. Samson T, Smyth N, Janetzky S, Wendler O, Müller JM, Schüle R, von der Mark H, von der Mark K and Wixler V: The LIM-only proteins FHL2 and FHL3 interact with alpha- and beta-subunits of the muscle alpha7betal integrin receptor. J Biol Chem 279: 28641-28652, 2004.

41. McGrath MJ, Mitchell CA, Coghill ID, Robinson PA and Brown S. Skeletal muscle LIM protein 1 (SLIM11FHL1) induces alpha 5 beta 1 -integrin-dependent myocyte elongation. Am J Physiol Cell Physiol 285: C1513-C1526, 2003.

42. Witt CC, Witt SH, Lerche S, Labeit D, Back W and Labeit S: Cooperative control of striated muscle mass and metabolism by MuRF1 and MuRF2. EMBO J 27: 350-360, 2008.

43. Purcell NH, Darwis D, Bueno OF, Müller JM, Schüle R and Molkentin JD: Extracellular signal-regulated kinase 2 interacts with and is negatively regulated by the LIM-only protein FHL2 in cardiomyocytes. Mol Cell Biol 24: 1081-1095, 2004.

44. Knöll R, Hoshijima M, Hoffman HM, Person V, Lorenzen-Schmidt I, Bang ML, Hayashi T, Shiga N, Yasukawa H, Schaper W, McKenna W, et al: The cardiac mechanical stretch sensor machinery involves a $\mathrm{Z}$ disc complex that is defective in a subset of human dilated cardiomyopathy. Cell 111: 943-955, 2002.

45. Zhou Q, Chu PH, Huang C, Cheng CF, Martone ME, Knoll G, Shelton GD, Evans S and Chen J: Ablation of Cypher, a PDZ-LIM domain Z-line protein, causes a severe form of congenital myopathy. J Cell Biol 155: 605-612, 2001.

46. Woo RA and Poon RY: Cyclin-dependent kinases and S phase control in mammalian cells. Cell Cycle 2: 316-324, 2003.

47. Barchiesi F, Jackson EK, Fingerle J, Gillespie DG, Odermatt B and Dubey RK: 2-Methoxyestradiol, an estradiol metabolite, inhibits neointima formation and smooth muscle cell growth via double blockade of the cell cycle. Circ Res 99: 266-274, 2006.

48. Yerushalmi R, Woods R, Ravdin PM, Hayes MM and Gelmon KA: Ki67 in breast cancer: prognostic and predictive potential. Lancet Oncol 11: 174-183, 2010. 